\title{
Polymer Composite Materials from Current Status to Future Prospects
}

\author{
Ayman S Al-Hussaini* \\ Department of Chemistry, Faculty of Science, Port Said University, Egypt
}

Submission: April 15, 2020; Published: May 06, 2020

*Corresponding author: Ayman S Al-Hussaini, Department of Chemistry, Faculty of Science, Port Said University, Egypt

\begin{abstract}
A call for novel material, new ideas, applications, and techniques are still and will be challenging all the time. The increased development of science and modern technology allows one to use a high-throughput search for novel materials that could give positive feedback in different areas of life. With increasing demand for high performance materials, the focus of recent researches has been to produce products with enhanced properties at minimal changes in the equipment, process and cost of inputs. The addition of clay minerals or nano-metal oxides to the polymers is to improve the polymer properties, their wide and demand characteristics or desired potential applications by producing the polymer nanocomposites. Scanning and transmission electron microscopy have led to a deeper understanding of polymer nanocomposites, a better account surface topology, structure and morphology.

Keywords: Polycondensation; $\mathrm{Tio}_{2}$; Core-Shell; $\mathrm{Fe}_{2} \mathrm{O}_{3}$;Tem; Photocatalytic Activity; $\mathrm{AL}_{2} \mathrm{O}_{3}$; Kaolinite; Bentonite; Nanocomposites
\end{abstract}

\section{Introduction}

During the last few decades, interest in polymer/clay nanocomposites (PCN) arena has speedily been increasing at an unprecedented level, both in academia and in industry, due to their enhanced physical, chemical, and mechanical properties compared to conventional bare polymers. They have the interesting potential of being a low-cost alternative to high-performance composites for commercial uses in both the packaging and automotive industries. The target of the addition of clay minerals to the polymers is to improve the polymer properties and to obtain polymer/clay nanocomposites with particular characteristics to be suitable for certain applications. Because of the availability, low price, high aspect ratio as well as interfacial interactions and wanted nanostructure, clays can provide dramatic and adaptable improved definite properties at very lower loadings which lead to the highest remaining of polymer original beneficial characteristics. The earliest attempt for the production of nanoparticles appears to have been stimulated by the Toyota scientific research group, where the practical usage of nylon-6-montmorillonite (MMT) nanocomposite has been commercialized [1-3].

\section{Discussion}

Various new polymers [4,5] and copolymer/bentonite [6-10], copolymer/kaolinite [11-13], copolymer/pyrogenic silica [14], terpolymer/ bentonite $[15,16]$, terpolymer/kaolinite $[17,18]$ composites have been reported. 3rOne of the composites types is core-shell polymers (CSPs). CSPs have attracted enormous research interest, both from the point of view of fundamental science and technological applications. One in principle forms the core and other forms the shell of the particles. This class of material has the combination of superior properties not possessed by the individual components. The systems might combine the characteristics and properties of both shell and core where the surface properties of the shell are translated to the core, imparting new functionality to the CSP. In continuation of our work, the current studies establishe a novel contribution to the development of new core-shell nanocomposites (CSNCs) based on $\mathrm{TiO}_{2}[19,20], \mathrm{Fe}_{2} \mathrm{O}_{3}$ [21], $\mathrm{Al}_{2} \mathrm{O}_{3}[22,23]$ nanoparticles, which were successfully synthesized by an in situ oxidative chemical polymerization.

\section{Conclusion}

An economical approach aimed at producing a series of promising polymer nanocomposites was successfully achieved by in situ polycondensation. Adaptable loads of clay minerals or nano-metal oxides were utilized. The representative spectral characteristics upon incorporation of clay minerals or nanometal oxides into the polymer sequences were investigated by means of FT-IR and UV-Vis spectroscopy, indicating the fruitful synthesis of the polymer nanocomposites from clay minerals 
or nano-metal oxides with original polymer. Furthermore, the thermal investigations revealed that clay minerals or nano-metal oxides incorporated into the polymer nanocomposites. Moreover, TEM demonstrated that this novel produced CSNC possessed approximately sphere-shaped core-shell structure with size 17$27 \mathrm{~nm}$. Moreover, photocatalytic efficiency of CSNCs towards MB was substantiated in sunlight. As a result of the synergetic interactions between $\mathrm{TiO}_{2}$ and the copolymer or terpolymer, the rapid charge isolating then gradual recombining accomplished under sunlight irradiations. Our system considered to have moderate stability, to be one of the good systems, and to have narrow PDI. This technique familiarizes a beneficial, simplistic and inexpensive setup to produce new potential CSNCs obsessed varied functionality. Further research could pave way for studying new polymer nanocomposites.

\section{References}

1. Okada A, Kawasumi M, Usuki A, Kojima Y, Kurauchi T, et al. (1990) Nylon 6-Clay Hybrid, Mater. Res Soc Symp Proc 171: 45.

2. Usuki A, Kawasumi M, Kojima Y, Okada A, Kurauchi T, et al. (1993) Swelling behavior of montmorillonite cation exchanged for $\omega$-amino acids by $\epsilon$-caprolactam. J Mater Res 8(5): 1174-1178.

3. Fornes TD, Yoon PJ, Keskkula H, Paul DR (2001) Nylon 6 nanocomposites: the effect of matrix molecular weight. Polymer 42(25): 9929-9940.

4. Al-Hussaini AS, Klapper M, Pakula T, Müllen K (2004) Poly(imino ketone)s as new high-performance polymers. Macromolecules 37(22): 8269-8277.

5. Al-Hussaini AS (2014) Synthesis and characterization of new thermally stable polymers as new high-performance engineering plastics. High Perform Polym 26(2): 166-174.

6. Al-Hussaini AS, Eldars W (2016) Cheap synthesis, characterization and antibacterial efficacy of new copoly(o-nitroaniline-co-ophenylenediamine) emeraldine base/bentonite composites. J Inorg Organomet Polym Mater 26: 691-701.

7. Al-Hussaini AS (2016) Inexpensive fabrication and characterization of crystalline poly(o-anthranilic acid-co-o-phenylenediamine) emeraldine base/bentonite nanocomposites. Polym Plast Technol Eng 55: 1386-1392.

8. Al-Hussaini AS (2018) Novel benzidine and o-phenylenediamine copolymer-matrix microcomposites. J Inorg Organomet Polym Mater 28: 871-879.

9. Al-Hussaini AS (2019) New crystalline poly(aniline-co-benzidine)/ bentonite microcomposites: synthesis and characterization. Polym Bull 76: 323-337.

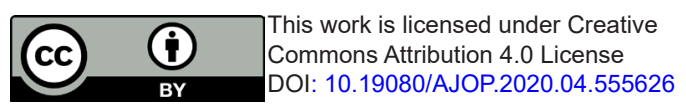

10. Al-Hussaini AS, Eldars W (2014) Non-conventional synthesis and antibacterial activity of poly(aniline-co-o-phenylenediamine) / bentonite nanocomposites. Des Monomers Polym 17(5): 458-465.

11. Al-Hussaini AS, Elias AM, Abd El-Ghaffar MA (2017) New poly(anilineco-o-phenylenediamine)/kaolinite microcomposites for water decontamination. J Polym Environ 25: 35-45.

12. Al-Hussaini AS (2017) In situ oxidative copolymerization and characterization of new poly(benzidine-co-o-phenylenediamine)/ kaolinite microcomposites. Polym Sci Ser B Polym 59: 372-378.

13. Al-Hussaini AS, Zoromba MS (2014) New crystalline aniline and o-anthranilic acid copolymer/kaolinite composites. Polym Plast Technol Eng 53: 1021-1027.

14. Al-Hussaini AS, Zoromba MS, El-Ghamaz NA (2013) In situ polymerization and characterization of aniline and o-anthranilic acid copolymer/pyrogenic silica nanocomposites. Polym Plast Technol Eng 52(11): 1089-1096.

15. Al-Hussaini AS (2020) Environmentally friendly synthesis of lightweight terpolymer/hydrophilic bentonite composites for water decontamination. J Inorg Organomet Polym Mater 30: 379-387.

16. Al-Hussaini AS (2015) Modified non-conventional synthesis of new terpoly(aniline, o-anthranilic acid and o-phenylenediamine) / bentonite composites. Polym Plast Technol Eng 54(1): 61-67.

17. Al-Hussaini AS, Elias AM, Abd El-Ghaffar MA (2019) New terpolymermatrix microcomposites for heavy metal removal. J Macromol Sci A 56(9): 887-898.

18. Al-Hussaini AS (2016) New polymeric based materials: Terpoly(aniline, diphenyl amine, and o-anthranilic acid)/kaolinite composites. Polym Adv Technol 27: 1604-1608.

19. Al-Hussaini AS, Eltabie KR, Rashad MEE (2016) One-pot modern fabrication and characterization of $\mathrm{TiO}_{2} @$ terpoly(aniline, anthranilic acid and o-phenylenediamine) core-shell nanocomposites via polycondensation. Polymer 101: 328-337.

20. Al-Hussaini AS, Eltabie KR, Hassan MER (2018) Fabrication of coreshell nanocomposites with enhanced photocatalytic efficacy. Polym Int 67(10): 1419-1428.

21. Ossoss KM, Hassan MER, Al-Hussaini AS (2019) Novel $\mathrm{Fe}_{2} \mathrm{O}_{3} @ P A N I-$ o-PDA core-shell nanocomposites for photocatalytic degradation of aromatic dyes. J Polym Res 26: 199.

22. Al-Hussaini AS, El-Bana WE, El-Ghamaz NA (2020) New semiconducting core-shell nanocomposites. Compos Interfaces 27: 385-399.

23. Al-Hussaini AS, El-Bana WE, El-Ghamaz NA (2020) New semiconductor core-shell based on nano-rods core materials. Polym Plast Technol Eng 59: 630-641.

Your next submission with Juniper Publishers will reach you the below assets

- Quality Editorial service

- Swift Peer Review

- Reprints availability

- E-prints Service

- Manuscript Podcast for convenient understanding

- Global attainment for your research

- Manuscript accessibility in different formats

( Pdf, E-pub, Full Text, Audio)

- Unceasing customer service

Track the below URL for one-step submission https://juniperpublishers.com/online-submission.php 